\title{
Effect of ambient temperature on the vertical distribution and movement of Pacific bluefin tuna Thunnus thynnus orientalis
}

\author{
Takashi Kitagawa ${ }^{1, *}$, Hideaki Nakata ${ }^{1}$, Shingo Kimura ${ }^{1}$, Tomoyuki Itoh ${ }^{2}$, \\ Sachiko Tsuji ${ }^{2}$, Akira Nitta ${ }^{3}$ \\ ${ }^{1}$ Ocean Research Institute, University of Tokyo, Nakano, Tokyo 164-8639, Japan \\ ${ }^{2}$ National Research Institute of Far Seas Fisheries, Fisheries Agency of Japan, Shimizu, Shizuoka 424-8633, Japan \\ ${ }^{3}$ Japan NUS Co., Ltd, Minato, Tokyo 108-0022, Japan
}

\begin{abstract}
Immature Pacific bluefin tuna Thunnus thynnus orientalis, marked with an archival tag, were released near Tsushima Island in the eastern East China Sea (58 individuals on 7 to 14 December 1995, 47 individuals on 29 November 1996). Of these, 15 were recovered by the following summer period. From the tags retrieved, we analyzed time-series data on swimming depth and ambient temperature recorded every $128 \mathrm{~s}$. Our main objectives were to determine diurnal and seasonal changes in the swimming depth of bluefin tuna and examine the effect of ambient temperature on their vertical distribution and movement. In winter, the bluefin swam within the surface mixed layer at shallower depths during the night than during the day; swimming depth displayed diel periodicity. Some individuals displaying marked diel periodicity tended to migrate further offshore (direction southwest), where greater temperature gradients in the vertical water column were observed. This indicates that diel vertical migration of bluefin tuna is a direct response to changes in the thermocline. However, as the thermocline developed further in summer, the bluefin spent most of their time at the surface, suggesting that bluefin avoid rapid temperature change at the thermocline by making behavioral thermoregulation. During the summer, however, the fish made frequent dives through the thermocline during the day, and diel periodicity of swimming depth was more prominent than that in winter. The purpose of this movement is considered to be foraging. In conclusion, spatial and seasonal changes of the vertical structure of ambient water temperature have a great effect on the vertical distribution and movement of the bluefin tuna.
\end{abstract}

KEY WORDS: Pacific bluefin tuna $\cdot$ Archival tag $\cdot$ Daily periodicity $\cdot$ Behavioral thermoregulation · Thermocline

Resale or republication not permitted without written consent of the publisher

\section{INTRODUCTION}

Pacific bluefin tuna Thunnus thynnus orientalis is one of the most important fishery resources in the neritic region of Japan. Their abundance has decreased over the past decade, requiring more detailed scientific information on their distribution and movement. Spawning grounds of the Pacific bluefin are located to the south of the Japanese Islands, while immature

*E-mail: takashik@ori.u-tokyo.ac.jp bluefin are mainly distributed all around Japan. The East China Sea (Fig. 1) is a well-known wintering habitat for the immature bluefin, and from this sea they often migrate to the Pacific or to the Sea of Japan in late spring-summer; some often migrate to the Gulf of Alaska-California region as well (Bayliff 1994), which is known as 'transpacific migration' (Orange \& Fink 1963, Clemens \& Flitter 1969). After spending 2 to $6 \mathrm{yr}$ in the eastern Pacific, the bluefin return to the western Pacific for spawning (Bayliff 1980). However, the mechanism for migration has not yet been clarified. 


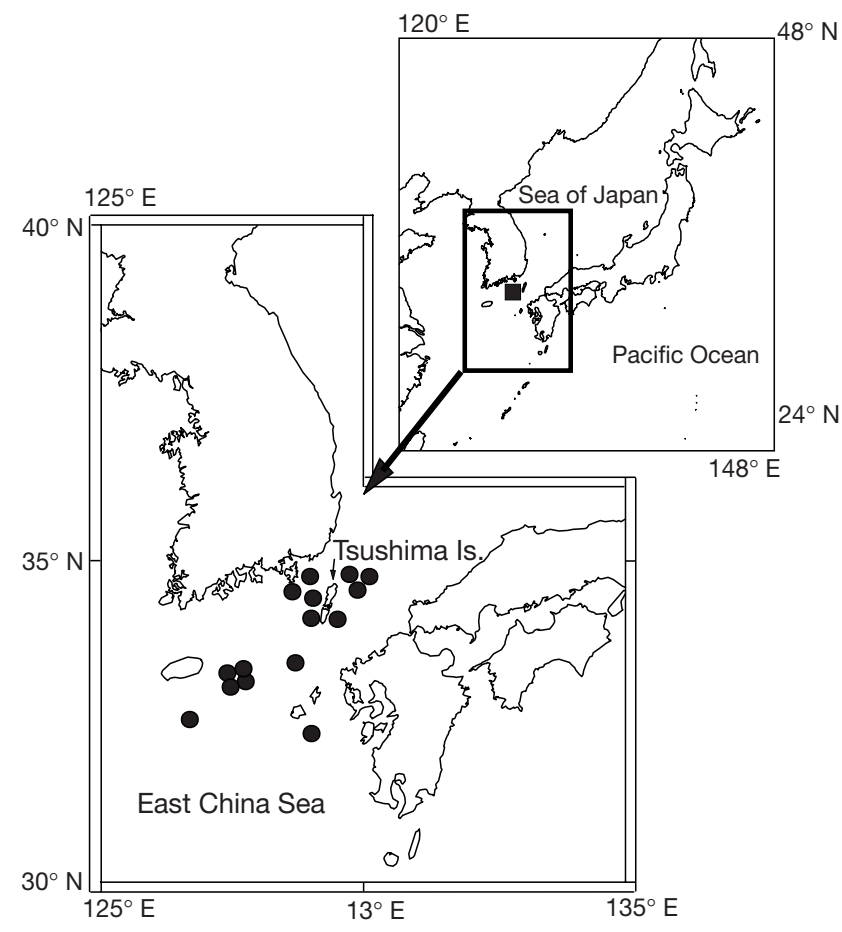

Fig. 1. Sites of release ( $\square$ ) and recovery $(\bullet)$ of Pacific bluefin tuna Thunnus thynnus orientalis marked with an archival tag

With regard to the vertical distribution and movement of the bluefin, information has been so far very limited and fragmentary. Recent biotelemetry studies revealed that vertical movement of yellowfin tuna Thunnus albacore was predominantly confined to the surface mixed layer above the thermocline (Carey \& Olson 1982, Holland et al. 1990, Cayré 1991, Block et al. 1997). This corresponds to the empirical finding that purse seine catches of yellowfin tuna and skipjack tuna Katsuwonus pelamis were considerably large in the thin mixed layers above sharp thermocline (Green 1967). Albacore tuna T. alalunga were on the other hand distributed in the region where vertical thermal difference was small (Kawasaki 1957), and their fishing grounds around Japan were formed outside and away from cold-water eddies where the depth of the permanent thermocline was shallow (Kawai 1980, Kimura et al. 1997). In contrast with the above species, bigeye tuna $T$. obesus were abundant in or below the thermocline (Suda et al. 1969). Bigeye tuna make large upward excursions, penetrating the thermocline in the daytime (Holland et al. 1992); this behavior is considered to be a result of 'physiological behavioral thermoregulation' (Holland et al. 1992). Although there has not yet been any detailed information on the bluefin, these findings suggest that seasonal change in vertical temperature structure would greatly affect the vertical distribution and movement of the bluefin.
In recent years, a micro datalogger such as an 'archival tag' has been developed and applied to a few fish species to clarify homing behavior of salmon (Boehlert 1997, Tanaka et al. 1998) and selective tidal transport of plaice (Metcalfe \& Arnold 1997). This recovery type datalogger enables us record time-series data for a longer duration and at a higher resolution compared to previous biotelemetry studies using various transmitters. Block et al. $(1997,1998)$ applied archival tags and pop-off satellite tags to Atlantic bluefin tuna Thunnus thynnus thynnus and studied their temporal and spatial movement patterns in the Atlantic Ocean. However, the authors only discussed the tagging methodology, and did not necessarily reveal the causal factor affecting movement of the fish.

In this study, we analyzed the comprehensive data on vertical distribution and movement of immature Pacific bluefin tuna obtained from the archival tags. Our main aims were to describe diurnal and seasonal changes in the swimming depth of the bluefin tuna, and to discuss the effect of ambient temperature and temperature gradients at the thermocline on the vertical distribution and movement. The behavioral characteristics of the bluefin in their vertical water column were also discussed in comparison with other tuna species.

\section{MATERIALS AND METHODS}

The main body of the archival tag (Northwest Marine Technology [NMT], Inc., WA, USA) used in the present study was $100 \mathrm{~mm}$ in length and $16 \mathrm{~mm}$ in diameter, with a weight (in air) of $52 \mathrm{~g}$. A thin, flexible stalk, $150 \mathrm{~mm}$ long and $2.2 \mathrm{~mm}$ in diameter, was attached to the main body. The sensors for light and external temperature measurement were embedded in the end of the stalk, whereas those for pressure and internal temperature measurement were installed in the main body of the tag. The external and internal temperatures, swimming depth, and ambient light levels were all measured at an interval of 128 s (675 data $\mathrm{d}^{-1}$ ) for a maximum of $80 \mathrm{~d}$.

In addition, fish locations were roughly estimated every day from the time of sunrise and sunset detected by the light sensor, and ambient temperatures at 3 depths $(0,61$, and $122 \mathrm{~m})$ were recorded once a day during the whole period of tracking. The data stored by the tag were analyzed in the laboratory using an IBM compatible PC with an NMT adapter.

Pacific bluefin tuna Thunnus thynnus orientalis were captured by troll near Tsushima Island (Fig. 1). Of these, 105 immature tunas, with a fork length of 45 to $78 \mathrm{~cm}$ and $\leq 1 \mathrm{yr}$ old (Yukinawa \& Yabuta 1967), were selected for tagging. The tunas marked with the archival tags were released near Tsushima Island on 2 
different occasions: 58 individuals on 7 to 14 December 1995 and 47 individuals on 29 November 1996.

In 1995, data was recorded for the initial $40 \mathrm{~d}$ after switching the tags on, and the for an additional $40 \mathrm{~d}$ before reading the data. In 1996, on the other hand, the data was recorded for $20 \mathrm{~d}$ after switching the tags on, and then for a further $60 \mathrm{~d}$ before reading the data. Therefore, when the tags were recovered more than $80 \mathrm{~d}$ after the release of the tuna 2 time-slots had been recorded: the initial 20 to $40 \mathrm{~d}$ and the latest 40 to $60 \mathrm{~d}$ at most.

Disinfected archival tags were inserted into the abdomen 4 to $5 \mathrm{~cm}$ above the anus by surgery. According to a breeding experiment made in a fish preserve for 123 to $453 \mathrm{~d}$ after attaching tags (Itoh unpubl.), bluefin tuna needed less than $1 \mathrm{wk}$ to resume foraging. In addition, data records of the peritoneal cavity (internal) temperature did not indicate that negative responses occurred following tag attachment.

Of the 105 individuals released by fisheries in the East China Sea 15 (5 in 1995 and 10 in 1996) were recovered (Fig. 1). The duration of the data record for each individual recovered is shown in Fig. 2. Nine out of 15 individuals were recovered within 2 mo after release, while the other 6 individuals were recovered within 4 to 7 mo after the release.

From the archival tags retrieved, we could obtain time-series data on the swimming depth, ambient water temperature, peritoneal cavity (internal) temperature, and ambient light level, which were all recorded every $128 \mathrm{~s}$. The light level data were mainly used for differentiating daytime from nighttime. In the present study, since we mainly discuss the vertical distribution and movement of the Pacific bluefin in relation to the ambient water temperature, the detailed results on the

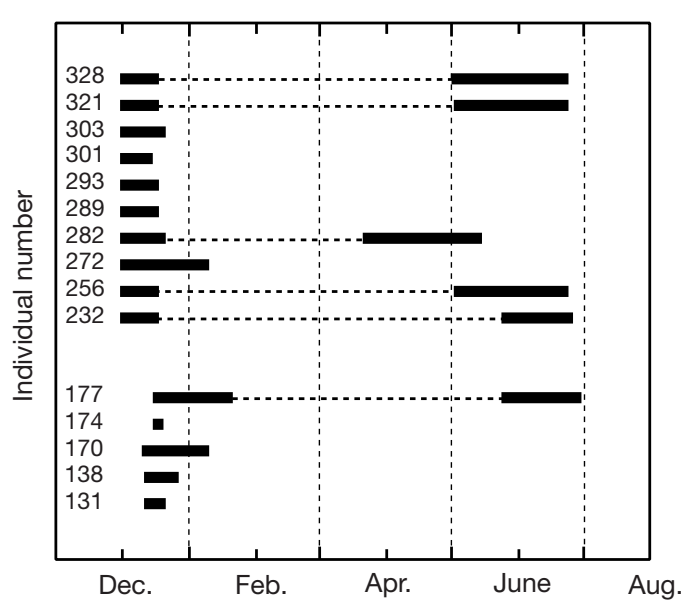

Fig. 2. Duration of the data record for each individual recovered. The lower 5 individuals were released on 7 to 14 December 1995, and the others were released on 29 November 1996 time series of peritoneal cavity temperature will be described in another paper.

\section{RESULTS}

\section{Average swimming depth}

The time-series data obtained for Bluefin 177 in winter (15 December 1995 to 21 January 1996) and in summer (24 May 1996 to 30 June 1996) are shown in Figs. 3 \& 4, respectively. In winter (November to January in this study), although the bluefin made diel vertical migration up to $120 \mathrm{~m}$ depth in the daytime and stayed at shallower depths in the nighttime, the ambient temperature did not change so much in association with the large vertical migration (Fig. 3). This small change is attributed to strong vertical mixing due to surface cooling. Bluefin 177 reached average nighttime and daytime depths of 25.5 and $59.3 \mathrm{~m}$, respectively, as summarized in Table 1 . In contrast, summer (March to June in this study) was characterized as a stratified season. The bluefin spent most of its time at the surface in both the daytime and nighttime, and frequently dived to depth through the thermocline during the day (Fig. 4). The diving resulted in a marked change in ambient temperature because of the existence of a seasonal thermocline below the surface mixed layer. The maximum diving depth also reached $120 \mathrm{~m}$ in summer; however, the average depth in the daytime $(0.8 \mathrm{~m})$ was shallow and not so different from that in the nighttime $(3.9 \mathrm{~m})$. This implies that diving serves a specific biological function that differs from the activity in the most frequented habitat above the thermocline.

The average depth for all individuals in December ranged from 23.3 to $32.1 \mathrm{~m}$ in the nighttime and from 26.8 to $70.5 \mathrm{~m}$ in the daytime (Table 1), significantly greater than those in June, which ranged from 0.8 to $6.3 \mathrm{~m}$ in the nighttime and 2.4 to $15.2 \mathrm{~m}$ in the daytime (Kruskal-Wallis test followed by Games-Howell, p < 0.0001). The difference between the average daytime and nighttime depth in June was also significant for 5 individuals (Kruskal-Wallis test followed by GamesHowell, $\mathrm{p}<0.0001$ ), though it was not large. The average swimming depth of Bluefin 177, which is represented in Figs. $3 \& 4$, was similar to that for the other individuals.

\section{Relationships between the swimming depth and ambient temperature}

Fig. 5 shows frequency distributions of the swimming depth together with mean vertical distribution of ambient temperature during the same period recorded 
(u) $47 \mathrm{~d}$ dəO

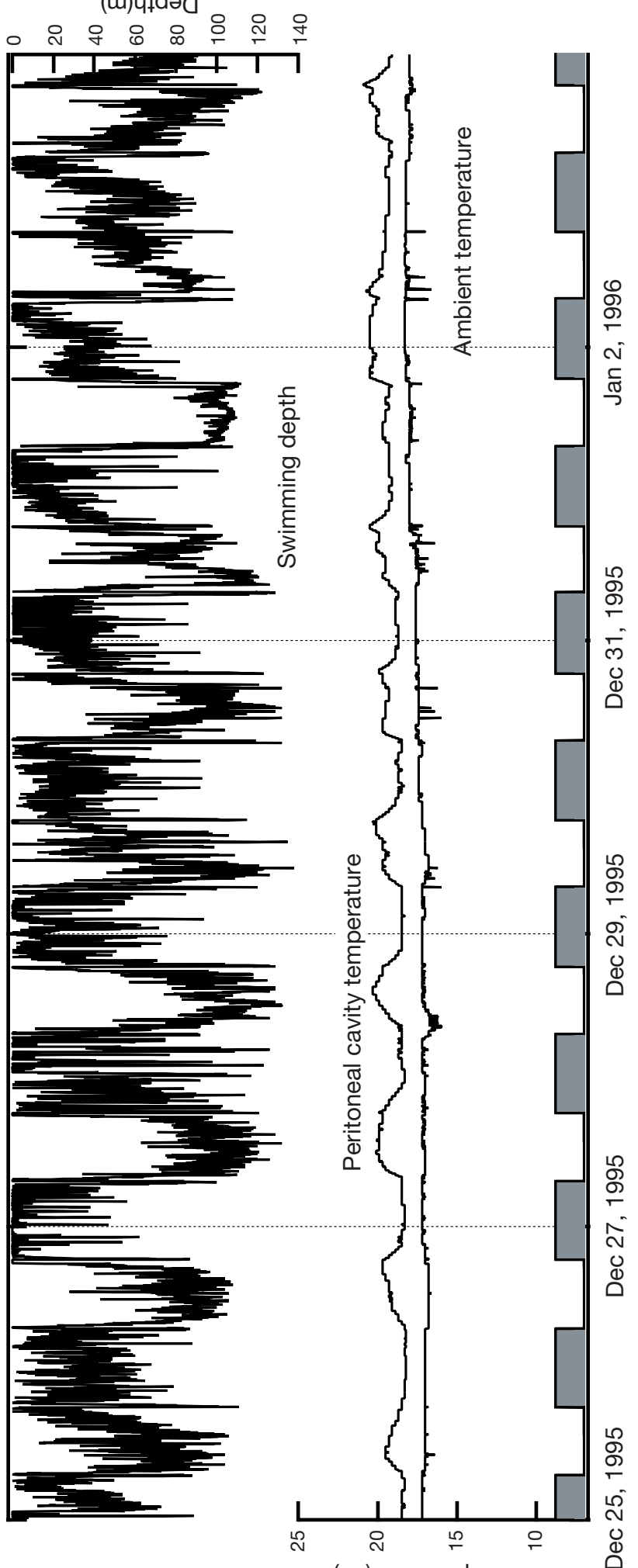

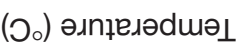

(u) $47 \mathrm{~d} \partial 0$
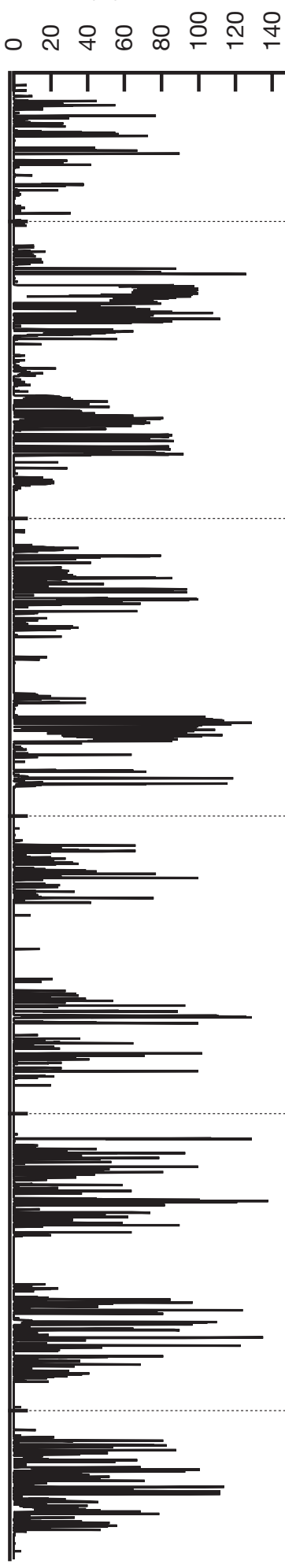

交

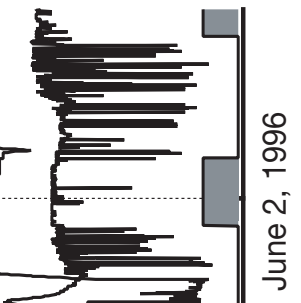

밈

:

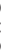

굴

S

苞

ह्व

?

宁 $\frac{\tilde{0}}{\tilde{7}}$

芩

ᄂ छู

o $\gg$

ले ฮु

无.

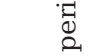

(

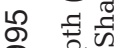

․

నे

○

䆑

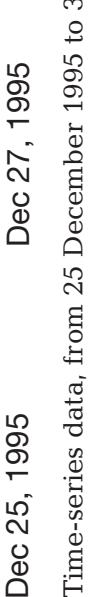

m

क्ष 
Table 1. Swimming depth of individual bluefin in December and in June. The Kruskal-Wallis test was used for indicating the statistical significance of the difference among the swimming depth during daytime in December, nighttime in December, daytime in June and nighttime in June. The Mann-Whitney $U$-test was used to indicate the statistical significance of the difference between daytime and nighttime in December for the lower 10 individuals

\begin{tabular}{|c|c|c|c|c|c|}
\hline $\begin{array}{l}\text { Bluefin } \\
\text { No. }\end{array}$ & $\begin{array}{c}\text { Nighttime } \\
\text { in December } \\
\text { Mean } \pm \text { SD }(\mathrm{m})\end{array}$ & $\begin{array}{c}\text { Daytime } \\
\text { in December } \\
\text { Mean } \pm \text { SD }(\mathrm{m})\end{array}$ & $\begin{array}{c}\text { Nighttime } \\
\text { in June } \\
\text { Mean } \pm \text { SD }(\mathrm{m})\end{array}$ & $\begin{array}{c}\text { Daytime } \\
\text { in June } \\
\text { Mean } \pm \text { SD }(\mathrm{m})\end{array}$ & $\begin{array}{l}\text { Kruskal-Wallis test or } \\
\text { Mann-Whitney } U \text {-test } \\
\text { p-value }\end{array}$ \\
\hline 177 & $25.5 \pm 26.4$ & $59.3 \pm 34.7$ & $0.8 \pm 5.4$ & $3.9 \pm 14.0$ & $<0.0001$ \\
\hline 232 & $27.3 \pm 17.3$ & $26.9 \pm 19.6$ & $2.2 \pm 8.3$ & $12.2 \pm 22.8$ & $<0.0001$ \\
\hline 256 & $23.5 \pm 18.1$ & $30.1 \pm 23.3$ & $1.8 \pm 9.4$ & $6.3 \pm 19.6$ & $<0.0001$ \\
\hline 321 & $23.3 \pm 19.3$ & $26.8 \pm 22.5$ & $0.9 \pm 4.9$ & $15.2 \pm 24.3$ & $<0.0001$ \\
\hline 328 & $26.7 \pm 17.4$ & $31.3 \pm 23.1$ & $6.3 \pm 17.5$ & $2.4 \pm 7.9$ & $<0.0001$ \\
\hline 131 & $29.2 \pm 29.7$ & $38.4 \pm 29.9$ & & & $<0.0001$ \\
\hline 138 & $28.9 \pm 26.6$ & $70.5 \pm 29.2$ & & & $<0.0001$ \\
\hline 170 & $30.6 \pm 33.5$ & $53.8 \pm 38.7$ & & & $<0.0001$ \\
\hline 174 & $30.9 \pm 32.6$ & $42.8 \pm 28.9$ & & & $<0.0001$ \\
\hline 272 & $25.4 \pm 18.4$ & $33.4 \pm 23.6$ & & & $<0.0001$ \\
\hline 282 & $29.3 \pm 24.3$ & $51.3 \pm 35.3$ & & & $<0.0001$ \\
\hline 289 & $29.0 \pm 17.0$ & $29.6 \pm 20.9$ & & & 0.6729 \\
\hline 293 & $25.1 \pm 18.1$ & $31.9 \pm 27.6$ & & & $<0.0001$ \\
\hline 301 & $24.7 \pm 26.9$ & $30.9 \pm 19.7$ & & & $<0.0001$ \\
\hline 303 & $32.1 \pm 19.6$ & $44.2 \pm 33.2$ & & & $<0.0001$ \\
\hline Total & $27.1 \pm 22.4$ & $39.1 \pm 30.8$ & $1.6 \pm 7.3$ & $6.1 \pm 17.2$ & \\
\hline
\end{tabular}

by the tag attached to Bluefin 177. In December, vertical profiles of ambient temperature (around $17.4^{\circ} \mathrm{C}$ ) seemed almost homogeneous above $100 \mathrm{~m}$ depth. The bluefin spent most of its time at the surface in the nighttime, although it also spent some time in deeper layers; however, during the day, there seemed to be no

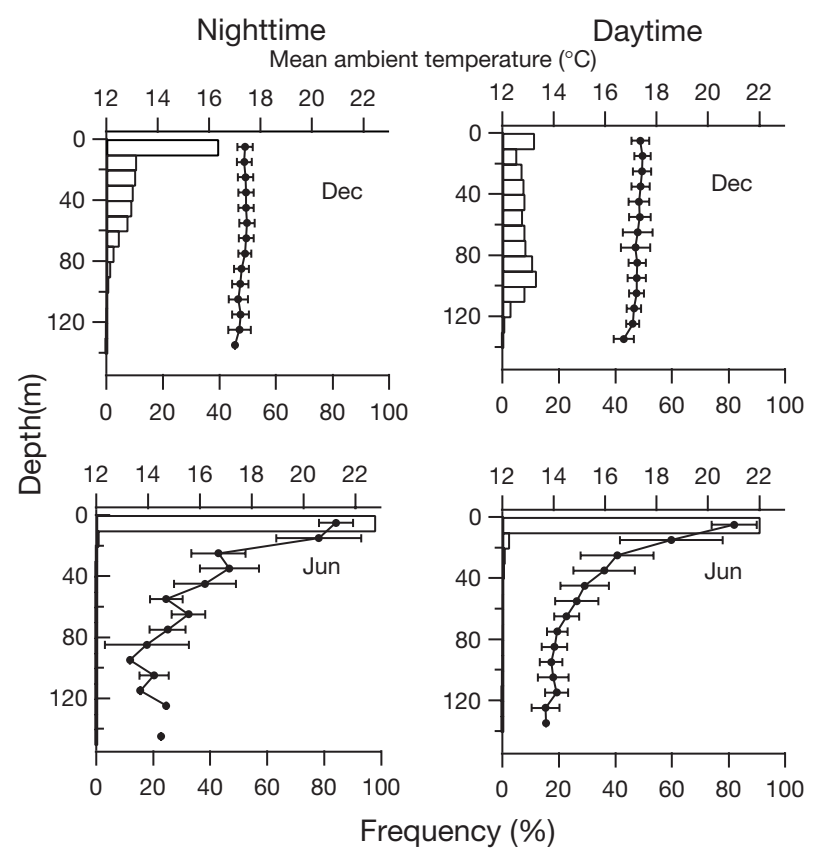

Fig. 5. Frequency distributions of the swimming depth of Bluefin 177 and vertical profiles of mean ambient temperature and SD in the daytime or nighttime preferred depth of occurrence. In June, on the other hand, a seasonal thermocline developed and the swimming depth tended to be confined to the surface water ( 0 to $9 \mathrm{~m}$ ) in both the daytime and nighttime. This suggests that a seasonal thermocline possibly regulates vertical distribution of the bluefin.

Fig. 6 further shows the relationship between the thermal gradient and frequency of bluefin swimming in the surface water ( 0 to $9 \mathrm{~m}$ ) in the daytime. The thermal gradient was defined as the difference between the average temperature at the surface and that at a depth of 50 to $59 \mathrm{~m}$, indicating relative strength of the thermocline. In Fig. 6, when the thermal gradient be-

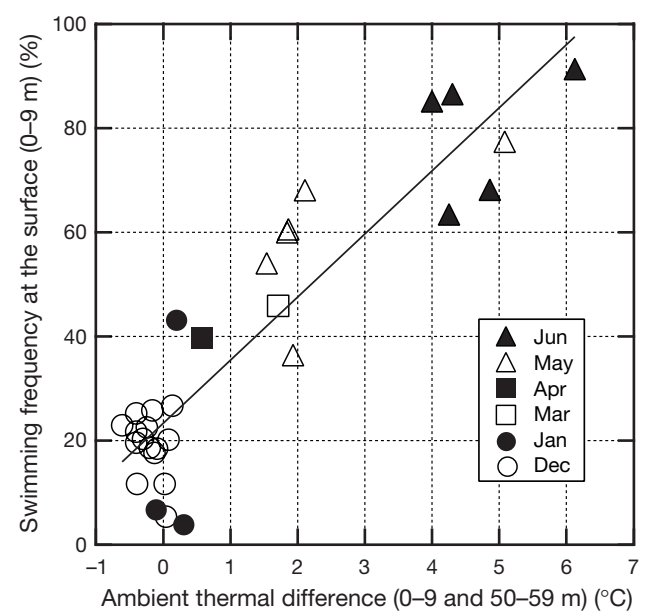

Fig. 6. Relationship between the thermal difference ( 0 to $9 \mathrm{~m}$ and 50 to $59 \mathrm{~m}$ ) and the frequency of swimming at the surface (0 to $9 \mathrm{~m})$ 
comes steeper, the bluefin spend much longer at the surface, suggesting that vertical structure of ambient temperature apparently affects the swimming depth of the bluefin. However, there may be an effect of temperature preference of the bluefin on this correlation, because higher surface temperature generally corresponds to larger temperature gradients. In fact, the average surface temperature ranged from 16.3 to $21.5^{\circ} \mathrm{C}$, which is significantly correlated with the frequency of bluefin swimming at the surface in the daytime. This suggests that there are interactions among 3 factors: the swimming frequency at the surface, the thermal gradient, and the average temperature of the surface water. Thus, partial correlations among these 3 factors were examined, in which the correlation between each pair of the 3 factors was calculated while the values of the other factor were held constant (Zar 1996). As a result, the correlation shown in Fig. 6 was significant (partial correlation coefficient $=0.839$, $\mathrm{p}<0.001$ ), while the correlation between the average temperature of the surface water and the swimming frequency at the surface was not significant (partial correlation coefficient $=-0.085, p>0.1$ ). These results strongly suggest that bluefin tuna tend to avoid vertical thermal change at the thermocline with the exception of frequent dives.
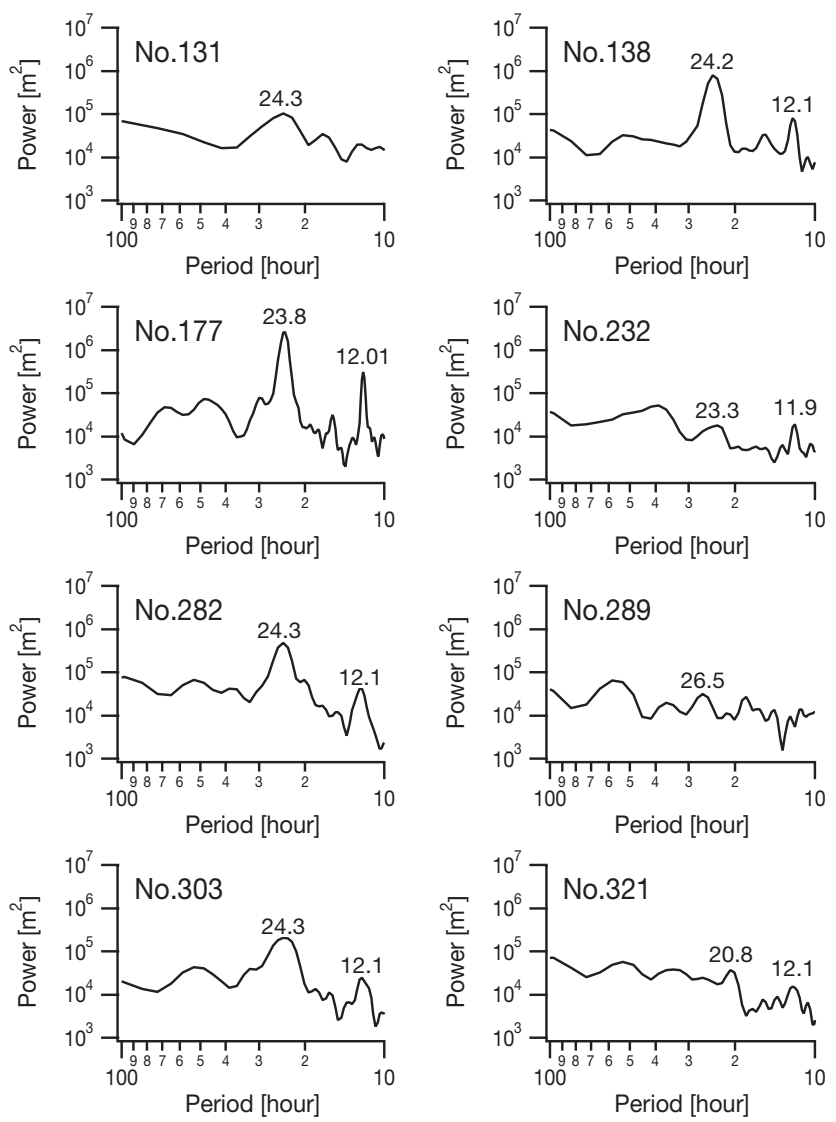

\section{Periodicity of the swimming depth variation}

In order to examine the periodicity of temporal variation in the swimming depth of bluefin, power spectra of the swimming depth of the time series data were calculated by fast Fourier Transform (FFT). Power spectra, whose periods ranged from 10 to $100 \mathrm{~h}$ for all individuals in winter, are shown in Fig. 7. Among 15 individuals 6 had a marked peak in the power spectrum of about $24 \mathrm{~h}$ (Bluefin 138, 170, 177, 272, 282, $303)$, indicating that bluefin made diel vertical migration, though the results for the others were indecisive. In Fig. 8, horizontal distributions of 3 individuals (Bluefin 138, 170, 177) with highest peaks around $24 \mathrm{~h}$ were further compared with those of 3 individuals (Bluefin 289, 321, 328) with lowest peaks. The ellipses in Fig. 8 have their center at the mean location of each individual, and the major and minor axes indicate the magnitude of the standard deviation; the major axis corresponds to the direction of the greatest geographic range of bluefin movement and the minor axis is orthogonal to the major one. If the distribution of bluefin in space follows a bivariate normal distribution, then the ellipse indicates a $40 \%$ confidence contour (Kendall \& Picquelle 1990). It is evident from Fig. 8 that the 3 individuals which had high peaks were widely
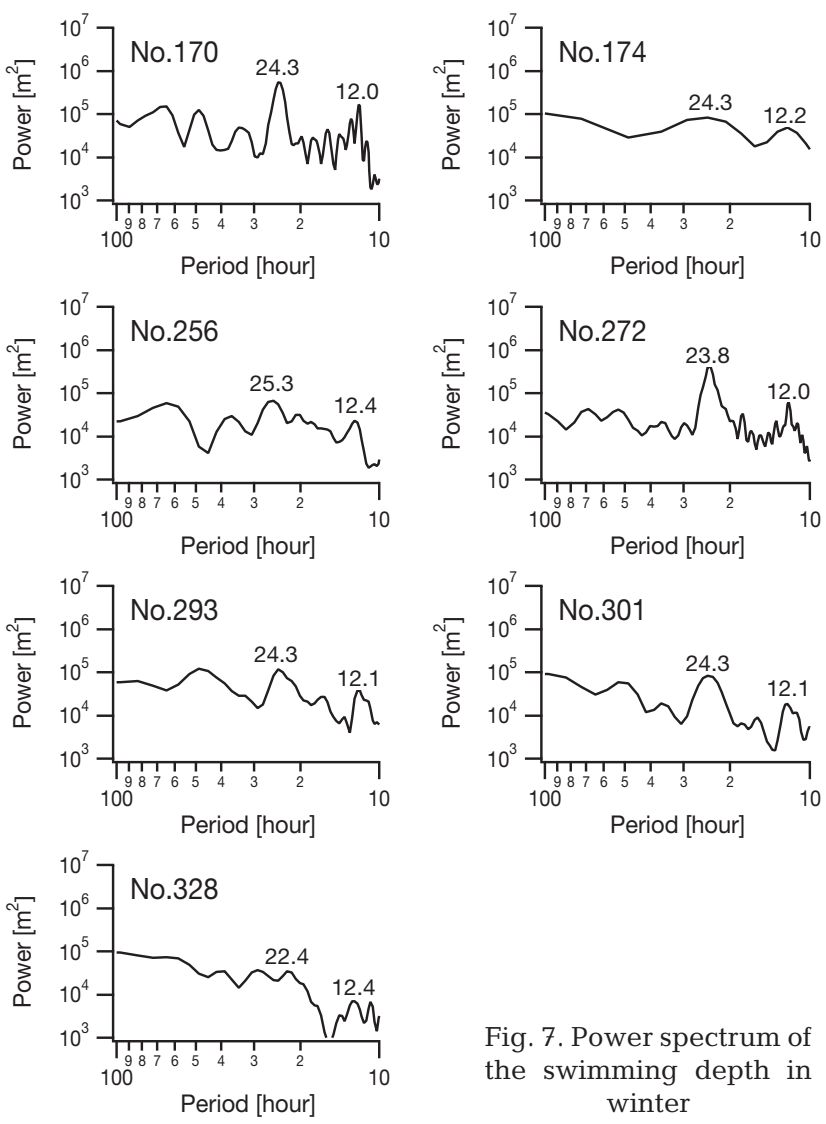

Fig. 7. Power spectrum of the swimming depth in winter 


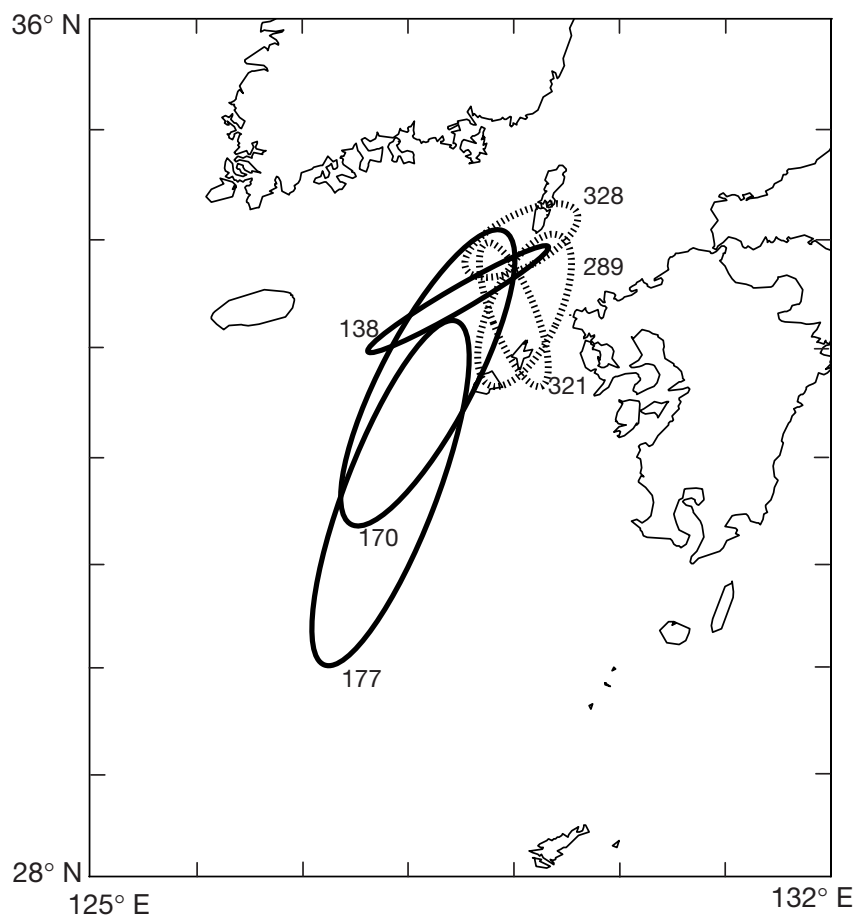

Fig. 8. Variance of the spatial distributions of 6 bluefin individuals in winter. Ellipses with solid line are for the individuals which showed high diel periodicity in power spectrum; broken ellipses are for those which showed no diel periodicity in power spectrum

distributed from the northeastern coast to southwest off the shore, while the horizontal coverage of those which had low peaks was small and mostly restricted to the coastal area. This suggests that the southwestward movement offshore could be related to the development of diel vertical migration.

In order to confirm the implication of the southwestward movement for the diel periodicity of swimming depth, the power spectra of Bluefin 177, which stayed around the northeastern coast in December and largely migrated southwestward in January, were reanalyzed for each period. The results for this comparison of the power spectra are shown in Fig. 9, together with corresponding vertical profiles of ambient temperature and frequency distributions of the swimming depth on the northeastern coast and southwest off the shore, respectively. The ambient temperature was around $18.5^{\circ} \mathrm{C}$ southwest off the shore, which was $0.9^{\circ} \mathrm{C}$ higher than that on the northeastern coast, and at depths below $100 \mathrm{~m}$, water temperature gradually dropped and a gentle thermocline was formed. Swimming depth was located at the top of the thermocline (around $100 \mathrm{~m}$ ) southwest off the shore and the pattern was more distinct than that on the northeastern coast. Apparently in response to the above features southwest off the shore, the diel periodicity became
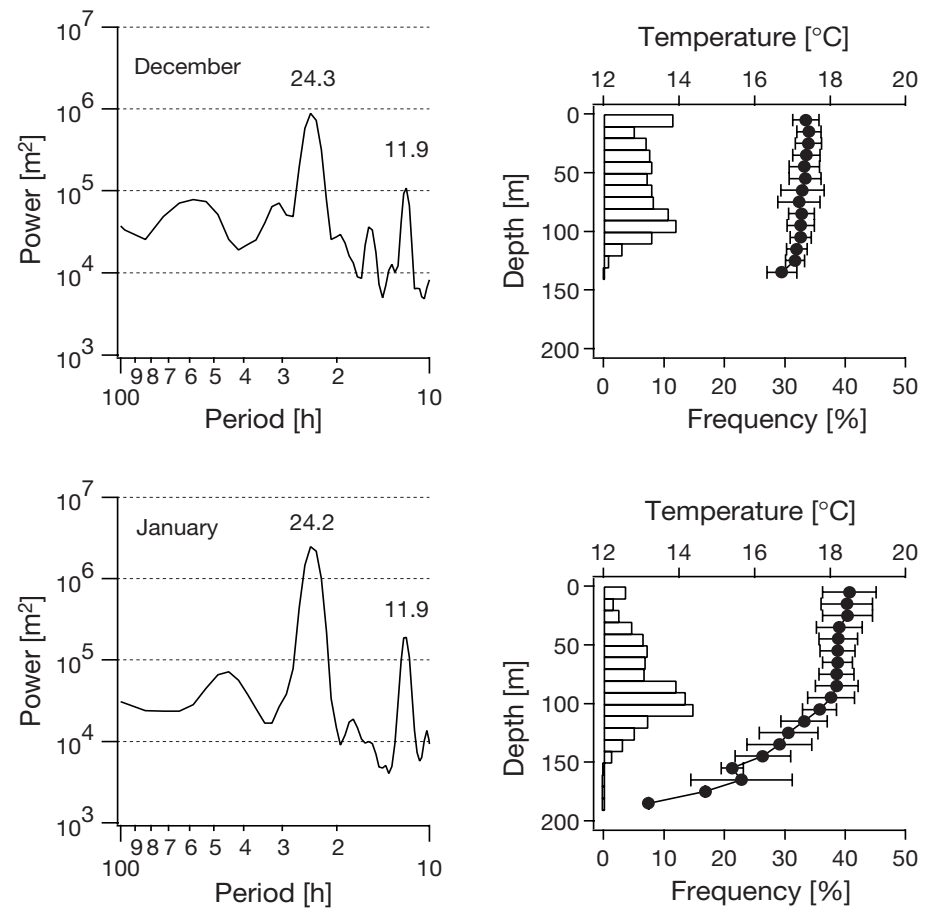

Fig. 9. Power spectrum of the swimming depth (left panels) and the frequency distributions of the swimming depth together with vertical distributions of mean ambient temperature and SD (right panels). Swimming depth and ambient temperature are based on the data obtained from Bluefin 177 on the northeastern coast in December (upper panels) and

southwest off the shore in January 1996 (lower panels)

more prominent there compared to that on the northwestern coast. However, the number of samples was low and the addition of data from a few more tagged bluefin could enhance the above results.

The periodicity in summer is shown in Fig. 10. There were high peaks in the power spectrum of about $24 \mathrm{~h}$ for all individuals. The bluefin spent most of their time at the surface in the nighttime and frequently dived to depth through the thermocline in the daytime under developed stratified conditions.

The secondary spectrum peaks were detected at about $12 \mathrm{~h}$ in most cases for both winter and summer (Figs. 7 \& 10). This periodicity was also strengthened by the southwestward movement (Fig. 9). Although the reason is still unclear, this periodicity is possibly related to tidal period.

\section{Peritoneal cavity temperature}

In winter, peritoneal cavity temperature was maintained a little higher than ambient temperature and increased by only a few degrees in the daytime (Fig. 3). Temperature increase in the daytime mostly resulted 

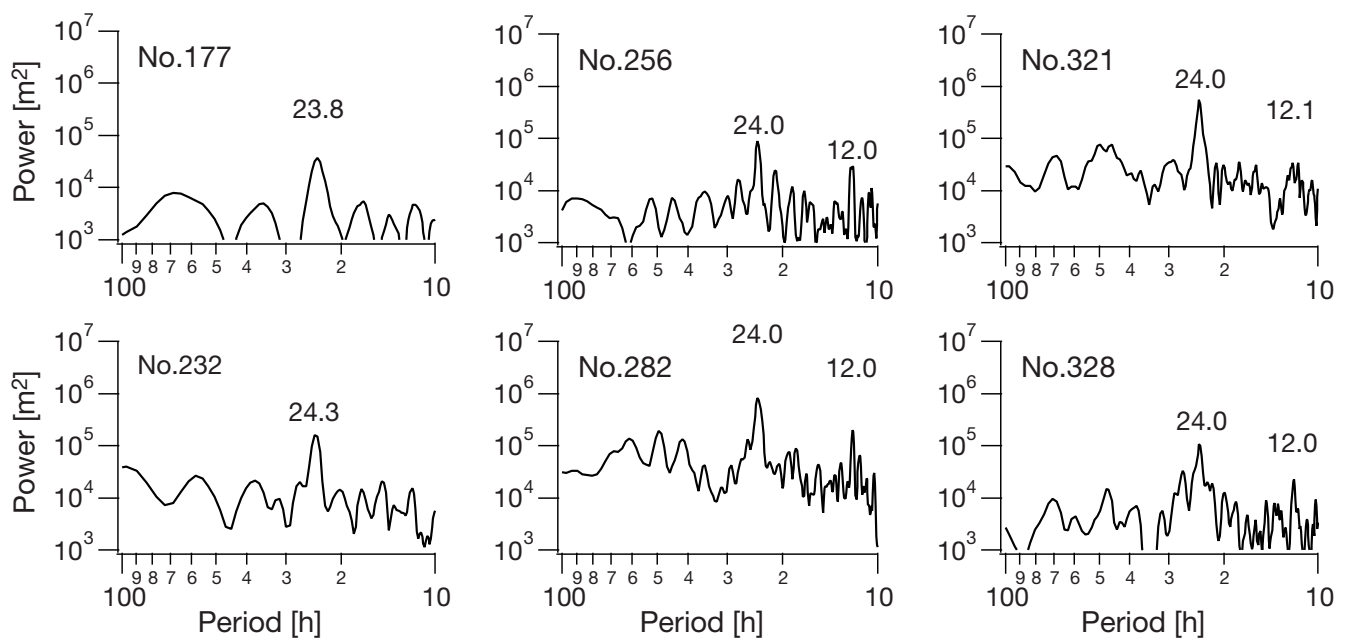

Fig. 10. Power spectrum of the swimming depth in summer

from greater heat production due to higher activity of the bluefin. In summer, on the other hand, the difference between peritoneal cavity and ambient temperatures was much larger than in winter (Fig. 4), suggesting that activity of the bluefin and heat production may increase from winter to summer. The peritoneal cavity temperature increased in the daytime, showing smallscale fluctuations corresponding to the frequent diving of the bluefin, and decreased in the nighttime. This suggests that the zigzag diving possibly produces heat in the body and thus contributes to the increase in the peritoneal cavity temperature in the daytime. This heat production may enable the bluefin to dive below the thermocline despite low ambient temperature.

\section{DISCUSSION}

An optimum temperature based on the surface temperature measured at the bluefin fishing ground by Uda (1957) has been used as an indicator of a good fishing ground. According to this measurement, the optimum water temperature for bluefin tuna ranged from 14 to $19^{\circ} \mathrm{C}$, and the favorable water temperature from 12 to $21^{\circ} \mathrm{C}$. In this study, the ambient water temperatures of the bluefin were almost within the range of the favorable water temperature $\left(16.3\right.$ to $\left.21.5^{\circ} \mathrm{C}\right)$. However, when the ambient water temperatures were even within the optimum water temperature, the swimming frequencies of the bluefin at the surface were not always high. In addition, no significant correlation was found between the swimming frequency and the water temperature at the surface, but the frequency was highly correlated with thermal gradients of the water. These results suggest that the swimming frequency at the surface does not depend on the optimum or favorable water temperatures themselves but depends on the vertical thermal gradients. Moreover it was clear that bluefin avoided rapid vertical thermal change at the thermocline and spent most of the time in the mixed layer with the exception of frequent dives both in summer and in winter.

In winter, bluefin swam in a shallower depth during the nighttime and in a deeper depth during the daytime, both within the surface mixed layer. The daily periodic fluctuation in the swimming depth was detected for most individuals of bluefin. This diel periodicity was also reported for other tuna species such as skipjack, yellowfin and bigeye (Dizon et al. 1978, Holland et al. 1990, Cayré 1991). Therefore, this diel vertical movement may be a common characteristic among tunas. Furthermore it is noticeable in this study that some individuals, which had high peaks in diel periodicity, tended to move far from the northeastern coast to southwest off the shore in the eastern East China Sea. By comparing the vertical profiles of the ambient temperature and the frequencies of the swimming depth between southwest off the shore and the northeastern coast, it was revealed that vertical stratification started to develop in a deeper layer southwest off the shore, and that bluefin tended to stay longer around the top of this thermal gradient during the daytime. Since this region is under strong influence from the Tsushima Warm Current, which is bifurcated from the Kuroshio (Masuzawa 1972), water mass characteristics could be different from the northwestern coast. This may stimulate motivation and enhance the diel periodicity of vertical migration of the bluefin.

In summer, on the other hand, the diel periodicity in the swimming depth became more prominent and was detectable for all of the bluefin individuals. This suggests that the diel vertical migration of the bluefin, as initiated in the region southwest off the shore in winter, further develops in summer, responding to strengthened stratification. In addition, change in the swimming pattern was also found in this period. 
Though bluefin spent most of their time at the surface in both the daytime and nighttime, they frequently moved, penetrating the lower temperature water of the thermocline in the daytime. This behavior was also reported for other tuna species such as yellowfin and albacore (Carey \& Olson 1982, Hunter et al. 1986, Block et al. 1997). Regarding the purpose of diving below the thermocline for yellowfin, Block et al. (1997) interpreted this as behavior for avoiding predator or ship. Holland et al. (1992), on the other hand, considered the diving in bigeye to be for foraging purposes. The purpose of the diving in immature bluefin is perhaps the latter because the frequency of the diving is quite high and it occurs mostly in the daytime.

According to Yamanaka \& staff (1963), bluefin tuna (20 to $65 \mathrm{~cm}$ in length) consume anchovies and other fish, plus crustaceans and squid. Although anchovies are generally pelagic fish, their swimming depth tends to be slightly deeper in the daytime in spring-summer (Nozu 1966), and the greatest swimming depth for anchovies was $125 \mathrm{~m}$ in spring and $70 \mathrm{~m}$ in summer (Nozu 1966). Yokota et al. (1961) reported that demersal lanternfishes were found in the bluefin stomach. Furthermore, Maurolicus muelleri, which is most dominant in micronekton in the East China Sea and the Sea of Japan and has been reported as a food of bluefin (Dragovich 1969), is distributed up to $150 \mathrm{~m}$ depth in the daytime (Ohshimo 1998). These reports give support to the hypothesis that the diving behavior may be related to foraging.

Then, why does bluefin tuna avoid large temperature gradients at the thermocline? According to Holland et al. (1992), bigeye tuna remain below the thermocline for long durations due to physiological and behavioral thermoregulation. It is evident from their analysis that the heat exchangers of the bigeye are disengaged to allow rapid warming as they ascend from cold water into warmer surface waters, and are reactivated to conserve heat when they return to the depths. However, the immature Pacific bluefin may not have such an effective physiological thermoregulation system, but may thermoregulate by spending most of its time at the surface. This is a possible reason why the bluefin made frequent dives to depth through the thermocline during the daytime. We intend to discuss detailed thermoregulation in the bluefin using timeseries data on peritoneal cavity temperature in another paper.

Acknowledgements. We wish to thank the Fishery Agency of Japan for allowing us to use the archival tag data. We are grateful to Z. Suzuki, Y. Ishizuka, and H. Yamada, National Research Institute of Far Seas Fisheries, for their useful comments. We also thank T. Sugimoto, Ocean Research Institute, University of Tokyo, for his encouragement during the study.

\section{LITERATURE CITED}

Bayliff WH (1980) Synopsis of biological data on the northern bluefin tuna, Thunnus thynnus (Linnaeus, 1758), in the Pacific Ocean. Inter-Am Trop Tuna Comm Spec Rep 2:261-293

Bayliff WH (1994) A review of the biology and fisheries for northern bluefin tuna, Thunnus thynnus, in the Pacific Ocean. FAO Fish Tech Pap 336:244-295

Block BA, Keen JE, Castillo B, Dewar H, Freund EV, Marcinek DJ, Brill RW, Farwell C (1997) Environmental preferences of yellowfin tuna (Thunnus albacares) at the northern extent of its range. Mar Biol 130:119-132

Block BA, Dewar H, Williams T, Prince ED, Farwell C, Fudge D (1998) Archival tagging of Atlantic bluefin tuna (Thunnus thynnus thynnus). Mar Tech Soc J 32:37-46

Boehlert GW (1997) Application of acoustic and archival tags to assess estuarine, nearshore and offshore habitat utilization by salmoids: introduction and objectives of the workshop. In: Boehlert GW (ed) Application of acoustic and archival tags to assess estuarine, nearshore, and offshore habitat utilization and movement by salmonids. NOAA Tech Memo NMFS SWFSC 236:1-6

Carey FG, Olson RJ (1982) Sonic tracking experiments with tunas. Int Comm Conserv Atl Tunas Col Vol Sci Pap 17: $458-466$

Cayré P (1991) Behaviour of yellowfin tuna (Thunnus albacares) and skipjack tuna (Katsuwonus pelamis) around fish aggregating devices (FADs) in the Comoros Island as determined by ultrasonic tagging. Aquat Living Resour $4: 1-12$

Clemens AE, Flitter GA (1969) Bluefin tuna migrate across the Pacific Ocean. Calif Fish Game 55:132-135

Dizon AE, Brill RW, Yuen HSH (1978) Correlations between environment, physiology, and activity and the effect on thermoregulation in skipjack tuna. In: Sharp GD, Dizon AE (eds) The physiological ecology of tunas. Academic Press, New York, p 233-259

Dragovich A (1969) Review of studies of tuna food in the Atlantic Ocean. US Fish Wildl Serv Spec Sci Rep Fish 593:1-21

Green RE (1967) Relationship of the thermocline to success of purse seining for tuna. Trans Am Fish Soc 96:126-130

Holland KH, Brill RW, Chang RKC (1990) Horizontal and vertical movements of yellowfin and bigeye tuna associated with fish aggregating devices. Fish Bull US 88:493-507

Holland KH, Brill RW, Chang RKC, Sibert JR, Fournier DA (1992) Physiological and behavioural thermoregulation in bigeye tuna. Nature 358:410-412

Hunter JR, Argue AW, Bayliff WH, Dizon AE, Fronteneau A, Goodman D, Seckel GR (1986) The dynamics of tuna movements: an evaluation of past and future research. FAO Fish Tech Pap 277:1-78

Kawai H (1980) Rings south of the Kuroshio and their possible roles in transport of the intermediate salinity minimum and information of the skipjack and albacore fishing grounds. In: The Kuroshio IV, Proc 4th CSK Symp Tokyo 1979. Saikon Publ Co, Tokyo, p 250-273

Kawasaki T (1957) Relation between the live-bait fishery of albacore and the oceanographical conditions in waters adjacent to a Japan: I. The fishing grounds south of the Kuroshio. Bull Tohoku Reg Fish Res Lab 9:69-110

Kendall AW Jr, Picquelle SJ (1990) Egg and larval distributions of walleye pollock Theragra chalcogramma in Shelikof Strait, Gulf of Alaska. Fish Bull US 88:133-154

Kimura S, Nakai M, Sugimoto T (1997) Migration of albacore, Thunnus alalunga, in the North Pacific Ocean in relation to large oceanic phenomena. Fish Oceanogr 6:51-57 
Masuzawa J (1972) Water characteristics of the north pacific central region. In: Stommel H, Yoshida K (eds) Kuroshio: its physical aspects. University of Tokyo Press, Tokyo, p 95-127

Metcalfe JD, Arnold GP (1997) Tracking fish with electric tag. Nature 387:665-666

Nozu J (1966) On the swimming layer of Engraulis japonica shoals in Bungo Channel and its adjacent waters. Bull Jpn Soc Sci Fish 32:237-241

Ohshimo S (1998) Distribution and stomach contents of Maurolicus muelleri in the Sea of Japan. J Korean Soc Fish Res 1:168-175

Orange CJ, Fink BD (1963) Migration of a tagged bluefin tuna across the pacific ocean. Calif Fish Game 49:307-309

Suda A, Kume S, Shiohama T (1969) An indicative note on a role of permanent thermocline as a factor controlling the long line fishing ground for bigeye tuna. Bull Far Seas Fish Res Lab 1:99-114

Editorial responsibility: Otto Kinne (Editor),

Oldendorf/Luhe, Germany
Tanaka H, Takagi Y, Iwata M, Naito Y (1998) The behavior and ambient temperature of homing chum salmon monitored by a data logger. Proc Natl Inst Pol Res Symp Polar Biol 11:62-73

Uda M (1957) A consideration on the long years trend of the fisheries fluctuation in relation to sea condition. Bull Jpn Soc Sci Fish 23:368-372

Yamanaka H, staff (1963) Synopsis of biological data on kuromaguro Thunnus orientalis (Temminck \& Schlegel) 1942 (Pacific Ocean). FAO Fish Rep 6:180-217

Yokota T, Toriyama M, Kanai F, Nomura S (1961) Studies on the feeding habit of fishes. Rep Nankai Reg Fish Res Lab $14: 1-23$

Yukinawa M, Yabuta Y (1967) Age and growth of blue tuna, Thunnus thynnus (Linnaeus), in the north Pacific Ocean. Rep Nankai Reg Fish Res Lab 25:1-18

Zar JH (1996) Biostatistical analysis, 3rd edn. Prentice-Hall, Englewood Cliffs, NJ

Submitted: December 17, 1999; Accepted: March 28, 2000

Proofs received from author(s): October 25, 2000 